\title{
Response surface optimization of electro-oxidation process for the treatment of C.I. Reactive Yellow 186 dye: reaction pathways
}

\author{
K. Rajkumar • M. Muthukumar
}

Received: 12 August 2014/Accepted: 19 February 2015/Published online: 11 March 2015

(C) The Author(s) 2015. This article is published with open access at Springerlink.com

\begin{abstract}
In this study, central composite design at five levels $(-\beta,-1,0,+1,+\beta)$ combined with response surface methodology has been applied to optimize C.I. Reactive Yellow 186 using electro-oxidation process with graphite electrodes in a batch reactor. The variables considered were the $\mathrm{pH}\left(X_{1}\right), \mathrm{NaCl}$ concentration $(\mathrm{M})\left(X_{2}\right)$, and electrolysis time $(\mathrm{min})\left(X_{3}\right)$ on C.I. Reactive Yellow 186 were studied. A second-order empirical relationship between the response and independent variables was derived. Analysis of variance showed a high coefficient of determination value $\left(R^{2}=0.9556\right.$ and 0.9416 for color and COD, respectively). The optimized condition of the electro-oxidation of Reactive Yellow 186 is as follows: $\mathrm{pH}$ 3.9; $\mathrm{NaCl}$ concentration $0.11 \mathrm{M}$; and electrolysis time $18 \mathrm{~min}$. Under this condition, the maximal decolorization efficiency of $99 \%$ and COD removal $73 \%$ was achieved. Detailed physico-chemical analysis of electrode and residues of the electro-oxidation process has also been carried out UVVisible and Fourier transform infrared spectroscopy. The intermediate compounds formed during the oxidation were identified using a gas chromatography coupled with mass spectrometry. According to these results, response surface methodology could be useful for reducing the time to treat effluent wastewater.
\end{abstract}

K. Rajkumar $(\bowtie) \cdot$ M. Muthukumar

Environmental Engineering and Technology Laboratory, Department of Environmental Sciences, Bharathiar University, Coimbatore 641 046, Tamilnadu, India

e-mail: rajkumar_env@yahoo.co.in

K. Rajkumar

M/S Sakthi Sugars Limited - Soya Division, Pollachi 643103, Tamilnadu, India
Keywords Electro-oxidation - C.I. Reactive Yellow 186 . Response surface methodology (RSM) · FTIR · GC-MS

\section{Introduction}

Textile manufacturing is one of the largest industrial producers of wastewater which produce approximately 125-150 L of water for $1 \mathrm{~kg}$ of textile product (USEPA 1995). Azo dyes are the most widely used dyes account for 60-70 \% of all textile dyestuffs used (Zollinger 1987) and major pollutants in dye effluents. Currently, there are more than 10,000 different textile dyes with an estimated annual production of $7 \times 10^{5}$ metric tones which are commercially available worldwide, of which reactive dyes are the leading class because of their wide applicability (Soloman et al. 2009). The textile and dyestuff industries are the main sources of dyes that are released to the environment. Since small quantities of dyes are clearly visible and detrimentally influence the water environment, hence, removing the color from wastewater is more important than treating other colorless organics. Conventional treatment cannot efficiently remove dyes from textile wastewater, because they are stable against light and biological degradation. Such treatments as adsorption, flotation, and coagulation only alter the phases of pollutants but do not destroy them. Moreover, new environmental laws may consider the spent adsorbents or sludge as hazardous wastes and require further treatment (Liu and Chiou 2005). Oxidation processes (OPs) are alternative methods for decolorizing and reducing recalcitrant wastewater loads. Considerable progress has been made in the development of OPs for textile effluent in recent years, especially in electro-oxidation processes. Many researchers have investigated the 
electrochemical oxidation for various types of effluent (Yahiaoui et al. 2014; Liu et al. 2010; Rajkumar and Muthukumar 2012).

In electrochemical process, the pollutants are destroyed by either a direct or an indirect oxidation process. These processes can be classified in two types: those which take place on the electrode surface, known as direct oxidation, and those which take place due to the action of molecules formed in the anode, known as indirect oxidation, the both processes can occur either in the same reactor. The process relies on the electrochemically generated oxidizing agent species such as hydroxyl radical $\left(\mathrm{OH}^{\bullet}: 2.80 \mathrm{eV}\right)$, chlorine $\left(\mathrm{Cl}_{2}: 1.36 \mathrm{eV}\right)$, hypochlorite $\left(\mathrm{OCl}^{-}: 1.72 \mathrm{eV}\right)$, ozone $\left(\mathrm{O}_{3}\right.$ : $2.07 \mathrm{eV})$, and hydrogen peroxide $\left(\mathrm{H}_{2} \mathrm{O}_{2}: 1.76 \mathrm{eV}\right)$, which can then be used to decompose dye molecule in the solution.

Response surface methodology (RSM) is essentially a particular set of mathematical and statistical method for designing experiments, building models, evaluating the effects of variables, and searching optimum conditions of variables to predict targeted responses (Myers and Montgomery 2002). It is an important branch of experimental design and a critical tool in developing new processes, optimizing their performance, and improving design and formulation of new products (Aktas et al. 2006). Recently, this optimization technique has been successfully applied to different processes, which includes electrochemical oxidation (Rajkumar and Muthukumar 2012; Yahiaoui et al. 2013; Yahiaoui et al. 2012), $\mathrm{O}_{3}$ oxidation (Muthukumar et al. 2004), and advanced oxidation process (Yahia Cherif et al. 2014). The most important factors employed into experimental design were $\mathrm{pH}, \mathrm{NaCl}$ concentration, and electrolysis time. In order to establish the interaction effect of variables, full-factorial central composite design (CCD) was used to optimize the variables for the maximum color and chemical oxygen demand (COD) removal.

\section{Materials and methods}

Chemicals

The oxidation processes were investigated using C.I. Reactive Yellow 186 (RY 186) (IUPAC name: benzenesulfonicacid,2-[2-[5-(aminocarbonyl)-1-ethyl-1,6-dihydro-2hydroxy-4-methyl-6-oxo-3-pyridinyl]diazenyl]-4-[[4-chloro6-[[3-[[2-(sulfooxy)ethyl]sulfonyl]phenyl] amino]-1,3,5triazin-2-yl]amino]-, sodium salt (1:2)). The azo dye was procured from Jansons International Ltd., Mumbai, India. The chemical structure and properties of the dye are enlisted in Table 1. Analytical grade hydrochloric acid, ferrous ammonium sulfate, potassium dichromate, sodium chloride, sodium hydroxide, sulfuric acid, mercuric sulfate (Loba chemie, Mumbai, India), and potassium bromide (Sigma-Aldrich) were used. The graphite sheet was procured from M/S Carbone Lorraine, Chennai, India.

Instruments and software

Electrolyses were preformed with a DC power supply (Sri Sai Scientific, Coimbatore, India). The synthetic wastewater $\mathrm{pH}$ was measured with a $\mathrm{pH}$ meter (Susima AP-1 Plus, Chennai, India). The removal of color was determined using UV-Visible spectrophotometer (Shimadzu 3600, Japan). Magnetic stirrer block (Superfit, Coimbatore, India) was used to keep contents well mixed during the experiment. After the treatment, the samples were centrifuged at $5000 \mathrm{rpm}$ for $10 \mathrm{~min}$ (Remi, Chennai, India). Then $0.45-\mu \mathrm{m}$ glass fiber attached syringe filter (Whatman,

Table 1 Properties of the dye C.I. Reactive Yellow 186

\begin{tabular}{llllll}
\hline Chemical structure & Molecular formula & Molecular weight & $\lambda$ max (nm) & CAS no: & Purity (\%) \\
\hline & & & & & \\
\hline
\end{tabular}


PVDF) was used to filter the sample obtained, which was used in GC-MS analysis. The residue generated after treatment was analyzed using FTIR spectrometer (Nicolet 10, USA). Scanning electron micrographs (SEM) images of graphite sheet before and after treatment were obtained using the scanning electron microscope (JEOL, JSM-5600, England). The intermediate formed during the processes was identified using GC (HP model 5890 Series II, USA) with coupled to a MS system (HP model 5972, USA). For the statistical interpretation of the data, regression analysis, graphical analysis, and analysis of variance (ANOVA) were performed with the help of a software package, Design Expert 8.0.4 Trial software (USA).

\section{Experimental design}

Response surface methodology (RSM) is an experimental technique invented to find the optimal response within the specified ranges of the factors. These designs are capable of fitting a second-order prediction equation for the response. In this study, three-level full-factorial CCD was adopted to optimize the electro-oxidation process variables. The variables chosen in this study were $\mathrm{pH}\left(X_{1}\right)$ : 3-11, electrolyte concentration $(\mathrm{NaCl})\left(X_{2}\right): 0.05-0.2 \mathrm{M}$, and electrolysis time $\left(X_{3}\right): 1-20 \mathrm{~min}$. The ranges and the levels of these variables investigated in this study are given in Table 2. Each variable in the design was studied at five different levels $(-1.6,-1,0,1,1.6)$. All variables were taken at a central coded value considered as zero. The experimental results of the CCD were fitted with a secondorder polynomial equation by a multiple regression technique as follows:

$$
\begin{aligned}
Y= & b_{0}+b_{1} X_{1}+b_{2} X_{2}+b_{3} X_{3}+b_{12} X_{1} X_{2}+b_{13} X_{1} X_{3} \\
& +b_{23} X_{2} X_{3}+b_{11} X_{1}^{2}+b_{22} X_{2}^{2}+b_{33} X_{3}^{2}
\end{aligned}
$$

where $Y$ is the predicted response; $b_{0}$ is the constant; $b_{1}, b_{2}$, and $b_{3}$ are the linear coefficients; $b_{12}, b_{13}$, and $b_{23}$ are the cross-product coefficients; and $b_{11}, b_{22}$, and $b_{33}$ are the quadratic coefficients. The color and COD removal were determined, and ANOVA was applied to obtain the interaction between the process variables and the responses. The quality of the fit of polynomial model was expressed by the coefficient of determination $R^{2}$ and $R_{\text {adj }}^{2}$ in
Eqs. (2) and (3), respectively. The statistical significance was checked with adequate precision ratio, $F$-values and $P$ values. The terms SS and DF correspond to sum of squares and degrees of freedom, respectively.

$R^{2}=1 \frac{\mathrm{SS} \text { residual }}{\mathrm{SS} \text { model }+\mathrm{SS} \text { residual }}$
$R_{\mathrm{adj}}^{2}=1 \frac{\mathrm{SS} \text { residual } / \mathrm{DF} \text { residual }}{(\mathrm{SS} \text { model }+\mathrm{SS} \text { residual }) /(\mathrm{DF} \text { model }+\mathrm{DF} \text { residual })}$

\section{Experimental set-up}

The electrolytic treatment of C.I. RY 186 containing wastewater was prepared synthetically in double-distilled water at a concentration of $500 \mu \mathrm{M}$. Each experimental run was performed as specified in the design matrix (Table 3). The experiments were conducted at room temperature in an open, undivided, and cylindrical batch glass reactor of $250 \mathrm{ml}$ capacity. The electrode assembly was placed in the reactor, and the electrodes were connected to the respective anode and cathode leads of the DC rectifier and energized for a required duration at a fixed current $(2.5 \mathrm{~A})$. The reactor was placed on a magnetic stirrer block in order to keep its contents well mixed during the experiment ( $\mathrm{Ra}$ jkumar and Muthukumar 2012). The effective surface area of both the anode and cathode of graphite electrodes was $6.5 \mathrm{~cm} \times 5.5 \mathrm{~cm}$, and the active electrode surface area was $71.5 \mathrm{~cm}^{2}$. The electrodes were positioned vertically and parallel to each other with an inter-electrode gap of $8 \mathrm{~mm}$ to reduce the ohmic losses.

\section{Analytical methods}

Samples were withdrawn at predetermined reaction times, with a hypodermic syringe and centrifuged at $5000 \mathrm{rpm}$ for 10 min prior to analysis. $\mathrm{pH}$ of the sample was analyzed before and after treatment using the $\mathrm{pH}$ meter and adjusted as per the design by adding $0.1 \mathrm{~N} \mathrm{HCl}$ and $0.1 \mathrm{~N} \mathrm{NaOH}$. The rate of decoloration was determined through absorbance at maximum wavelength $(\lambda \max 425 \mathrm{~nm})$ using UV-Visible spectrophotometer. Chemical oxygen demand was analyzed by open reflux method using the APHA standard method for wastewater analysis (Clesceri et al.

\begin{tabular}{|c|c|c|c|c|c|c|}
\hline \multirow[t]{2}{*}{ Variables, unit } & \multirow{2}{*}{$\begin{array}{l}\text { Factors } \\
\left(X_{j}\right)\end{array}$} & \multicolumn{5}{|c|}{ Range of actual and coded variables } \\
\hline & & -1.682 & -1.000 & 0 & +1.000 & +1.682 \\
\hline Initial $\mathrm{pH}, \mathrm{pH}_{0}$ & $\left(X_{1}\right)$ & 3 & 4.6 & 7 & 9.4 & 11 \\
\hline $\mathrm{NaCl}$ Conc., (M) & $\left(X_{2}\right)$ & 0.05 & 0.08 & 0.13 & 0.17 & 0.2 \\
\hline Time of electrolysis (min) & $\left(X_{3}\right)$ & 1 & 5 & 10.5 & 16 & 20 \\
\hline
\end{tabular}

Table 2 The level and range of variables chosen for electro-oxidation 
Table 3 Experimental design and responses for electro-oxidation of C.I. RY 186

\begin{tabular}{|c|c|c|c|c|c|c|c|}
\hline \multirow[t]{4}{*}{ Run no. } & \multicolumn{7}{|c|}{ Variables in uncoded levels } \\
\hline & \multirow{3}{*}{$\begin{array}{l}\left(X_{1}\right) \\
\mathrm{pH}\left(\mathrm{pH}_{0}\right)\end{array}$} & \multirow{3}{*}{$\begin{array}{l}\left(X_{2}\right) \\
\mathrm{NaCl}(\mathrm{M})\end{array}$} & \multirow{3}{*}{$\begin{array}{l}\left(X_{3}\right) \\
\text { Time (min) }\end{array}$} & \multicolumn{2}{|l|}{$Y_{1}$} & \multicolumn{2}{|l|}{$Y_{2}$} \\
\hline & & & & \multicolumn{2}{|c|}{ Color removal $(\%)$} & \multicolumn{2}{|c|}{ COD removal $(\%)$} \\
\hline & & & & Actual value & Predicted value & Actual value & Predicted value \\
\hline 1 & 7.00 & 0.13 & 10.50 & 98.22 & 98.97 & 51.23 & 51.25 \\
\hline 2 & 11.04 & 0.13 & 10.50 & 99.81 & 98.90 & 60.37 & 60.22 \\
\hline 3 & 7.00 & 0.05 & 10.50 & 98.21 & 97.01 & 40.71 & 45.54 \\
\hline 4 & 2.96 & 0.13 & 10.50 & 97.22 & 98.52 & 47.16 & 52.64 \\
\hline 5 & 7.00 & 0.13 & 19.75 & 99.49 & 95.35 & 62.24 & 67.22 \\
\hline 6 & 9.40 & 0.08 & 5.00 & 80.43 & 80.20 & 34.52 & 35.73 \\
\hline 7 & 4.60 & 0.17 & 16.00 & 99.32 & 99.28 & 62.24 & 57.24 \\
\hline 8 & 7.00 & 0.13 & 1.25 & 61.03 & 65.56 & 22.64 & 24.98 \\
\hline 9 & 4.60 & 0.08 & 5.00 & 83.57 & 81.05 & 28.30 & 23.43 \\
\hline 10 & 4.60 & 0.08 & 16.00 & 99.82 & 102.30 & 71.69 & 68.60 \\
\hline 11 & 9.40 & 0.17 & 16.00 & 98.33 & 100.58 & 52.83 & 53.93 \\
\hline 12 & 7.00 & 0.13 & 10.50 & 99.86 & 98.97 & 54.16 & 51.25 \\
\hline 13 & 9.40 & 0.17 & 5.00 & 89.17 & 86.41 & 47.16 & 46.48 \\
\hline 14 & 4.60 & 0.17 & 5.00 & 87.71 & 85.38 & 36.20 & 36.89 \\
\hline 15 & 7.00 & 0.13 & 10.50 & 98.85 & 98.97 & 52.84 & 51.25 \\
\hline 16 & 7.00 & 0.13 & 10.50 & 98.93 & 98.97 & 48.27 & 51.25 \\
\hline 17 & 9.40 & 0.08 & 16.00 & 99.66 & 101.72 & 72.47 & 68.02 \\
\hline 18 & 7.00 & 0.13 & 10.50 & 98.97 & 98.97 & 52.83 & 51.15 \\
\hline 19 & 7.00 & 0.20 & 10.50 & 98.11 & 99.69 & 44.52 & 45.01 \\
\hline 20 & 7.00 & 0.13 & 10.50 & 99.08 & 98.97 & 49.09 & 51.15 \\
\hline
\end{tabular}

1998). During electro-oxidation process, the treated sample was exposed to room temperature for $48 \mathrm{~h}$, followed by water evaporation and finally dry crystal deposition. A dry crystal was analyzed using FTIR spectrometer, and the crystal sample (10-15 mg) dispersed in $200 \mathrm{mg}$ of spectroscopic-grade $\mathrm{KBr}$ was recorded in the range of $4000-400 \mathrm{~cm}^{-1}$. The spectra were recorded on $\mathrm{KBr}$ disks of the dried sorbent. Before each measurement, the instrument was run to establish the background, which was then automatically subtracted from the sample spectrum. GC-MS was used for the identification of intermediate products during electro-oxidation process; the samples were collected at $20 \mathrm{~min}$. Before chromatography analysis, the sample was extracted using a separating funnel. Then, the oxidized samples of C.I. RY 186 treated sample were extracted with sequential aliquots of dichloromethane. Each extraction was performed three times with the addition of $20 \mathrm{~mL}$ solvents at each time. After extraction, the samples were concentrated to $100 \mu \mathrm{L}$ at $40{ }^{\circ} \mathrm{C}$ by water bath to evaporate and finally dissolved in $1 \mathrm{~mL}$ of $n$-hexane for analysis.

The injection of the extracted samples into GC-MS system was conducted on a split less mode, and injector temperature was $250{ }^{\circ} \mathrm{C}$ with helium served as the carrier gas at the flow rate of $1 \mathrm{~mL} \mathrm{~min}^{-1}$. The extracted samples were chromatographed using a chromatographic column [RTX-502.2 (L-60 m, ID-0.25 $\mu \mathrm{m}$ )] under the following temperature gradient: initially, the column temperature was held constant at $40{ }^{\circ} \mathrm{C}$ for $10 \mathrm{~min}$; increased from $12{ }^{\circ} \mathrm{C} \min ^{-1}$ to $100{ }^{\circ} \mathrm{C}$; ramped at $5^{\circ} \mathrm{C} \min ^{-1}$ to $200{ }^{\circ} \mathrm{C}$, and further ramped at $20^{\circ} \mathrm{C} \min ^{-1}$ to $270{ }^{\circ} \mathrm{C}$ and kept constant for $5 \mathrm{~min}$; and finally raised at $10^{\circ} \mathrm{C} \mathrm{min}^{-1}$ to $300{ }^{\circ} \mathrm{C}$

\section{Results and discussion}

Development of regression model equation

The statistical combinations of the critical variables, consisting of initial $\mathrm{pH}, \mathrm{NaCl}$ concentration, and electrolysis time, along with the maximum removal and predicted responses (decolorization/degradation efficiencies) are listed in Table 3. The regression coefficients of the response model and the $F$ - and $P$ values for RY 186 dye removal efficiencies are presented in Table 4. Further, it seems from Table 4 that the higher $F$-value indicates that most of the variation in the response can be explained by the regression 
equation. The associated $p$ value is used to estimate whether $F$ is large enough to indicate statistical significance, and $p$ value lower than 0.05 indicates that the model is statistically significant (Segurola et al. 1999). It was found that the $F$-value of 23.93 and 17.92 for color and COD removal, respectively, bears statistical significance. From the RSM results (Table 4), the regression model equations regardless the significance of the coefficients for both color and COD removal are developed and represented in the following Eqs. 4 and 5:

For color:

$$
\begin{aligned}
Y_{1}= & +98.97+0.11 X_{1}+0.80 X_{2}+8.86 X_{3} \\
& +0.47 X_{1} X_{2}+0.066 X_{1} X_{3}-1.84 X_{2} X_{3}-0.093 X_{1}^{2} \\
& -0.22 X_{2}^{2}-6.55 X_{3}^{2}
\end{aligned}
$$

For COD:

$$
\begin{aligned}
Y_{2}= & +51.25+2.25 X_{1}-0.16 X_{2}+13.15 X_{3}-0.68 X_{1} X_{2} \\
& -3.23 X_{1} X_{3}-6.20 X_{2} X_{3}+1.83 X_{1}^{2}-2.11 X_{2}^{2}-2.17 X_{3}^{2}
\end{aligned}
$$

Validation of the model

\section{Analysis of variance (ANOVA)}

ANOVA is a statistical technique that subdivides the total variation in a set of data into component parts associated with specific sources of variation for the purpose of testing hypotheses on the variables of the model (Huiping et al. 2007). The statistical significance of the ratio of mean square variation due to regression and mean square residual error was tested using ANOVA. The ANOVA results for color and COD removal are shown in Table 4. It indicates that the second-order polynomial models [Eqs. (4) and (5)] were highly significant and fitted to the experimental results well. The fit of the model gives coefficient of determination $R^{2}$ value of 0.9556 and an adjusted $R^{2}$ value of 0.9157 for color, and COD removal gives coefficient of determination $R^{2}$ value of 0.9416 and an adjusted $R^{2}$ value of 0.8891 . Therefore, the quadratic model was significant for color and COD removal.

\section{Adequacy check of the model}

Adequacy check of the proposed model is an important part of the analytical procedure. Good adequacy can ensure that the approximating model provides an adequate approximation to the real system; otherwise, it may give poor or misleading results (Korbahti and Rauf 2008). The diagnostic plots shown in Fig. 1 were used to estimate the adequacy of regression model. Studentized residuals in Fig. 1 are the residuals divided by the estimated standard deviation of that residual. It measures the number of standard deviations separating the actual and predicted values. The normal probability plot indicates whether the residuals follow a normal distribution, in which case the points will follow a straight line. S-shaped curve was not formed according to Fig. 1a and b, indicating that neither response transformation was needed nor there was any apparent problem with normality.

The actual and the predicted decolorization and COD

\begin{tabular}{|c|c|c|c|c|c|c|}
\hline & Source & Sum of squares & $d f$ & Mean square & $F$ value & Prob $>F$ \\
\hline \multirow[t]{7}{*}{ Color removal $\%$} & Model & 1733.02 & 9 & 192.56 & 23.93 & $<0.0001$ \\
\hline & Residual & 80.47 & 10 & 8.05 & & \\
\hline & Lack of fit & 79.09 & 5 & 15.82 & & \\
\hline & Pure error & 1.38 & 5 & 0.28 & & \\
\hline & Cor total & 1813.49 & 19 & 1813.49 & & \\
\hline & $R^{2}$ & 0.9556 & & & & \\
\hline & $R_{\mathrm{adj}}^{2}$ & 0.9157 & & & & \\
\hline \multirow[t]{7}{*}{ COD removal \% } & Model & 3020.31 & 9 & 335.59 & 17.92 & $<0.0001$ \\
\hline & Residual & 187.30 & 10 & 18.73 & & \\
\hline & Lack of fit & 160.40 & 5 & 32.08 & & \\
\hline & Pure error & 26.90 & 5 & 5.38 & & \\
\hline & Cor total & 3207.61 & 19 & & & \\
\hline & $R^{2}$ & 0.9416 & & & & \\
\hline & $R_{\mathrm{adj}}^{2}$ & 0.8891 & & & & \\
\hline
\end{tabular}
removal rate plot are shown in Fig. $2 \mathrm{a}$ and $\mathrm{b}$. The actual decolorization rate is the measured value for a particular run, and the predicted value is evaluated from the model. In

Table 4 Analysis of variance (ANOVA) for the fitted quadratic modal for color and COD removal 
designed experiments, $R^{2}$ is a measure of the amount of reduction in the variability of the response obtained using the independent variables in the model. A large value of $R^{2}$ does not imply that the regression model is a good one. However, adjusted $R^{2}$ is preferred to be used to determine the fit of a regression model as it does not always increase when variables are added. As shown in Fig. 3, a good agreement has been obtained between the predicted decolorization rate and the actually experimental value with (Table 4) $R^{2}$ and $R^{2}$ adjusted of 0.9556, 0.9157 and 0.9416, 0.8891 , respectively, for color and COD removal, which indicated that the proposed model had adequate approximation to the actual value.
Effect of variables on the color and COD removal

The perturbation plot for the color and COD removal is shown in Fig. 3. The plot was obtained at $7 \mathrm{pH}, 0.13 \mathrm{M}$ $\mathrm{NaCl}$, and electrolysis time at $10.5 \mathrm{~min}$. The rate response was drawn by changing only one factor over its range, while the other factors were held constant. A perturbation plot shows the comparison between all factors at a selected point in the considered design space. Comparatively, in both the case, flat line of time showed an insignificant effect of this factor on the reaction rate in the design space. In other words, the coefficient of $\mathrm{pH}$ was very low in Eq. (4). On the other
Fig. 1 Normal \% probability plot of the studentized residuals for color and COD (a), (b)
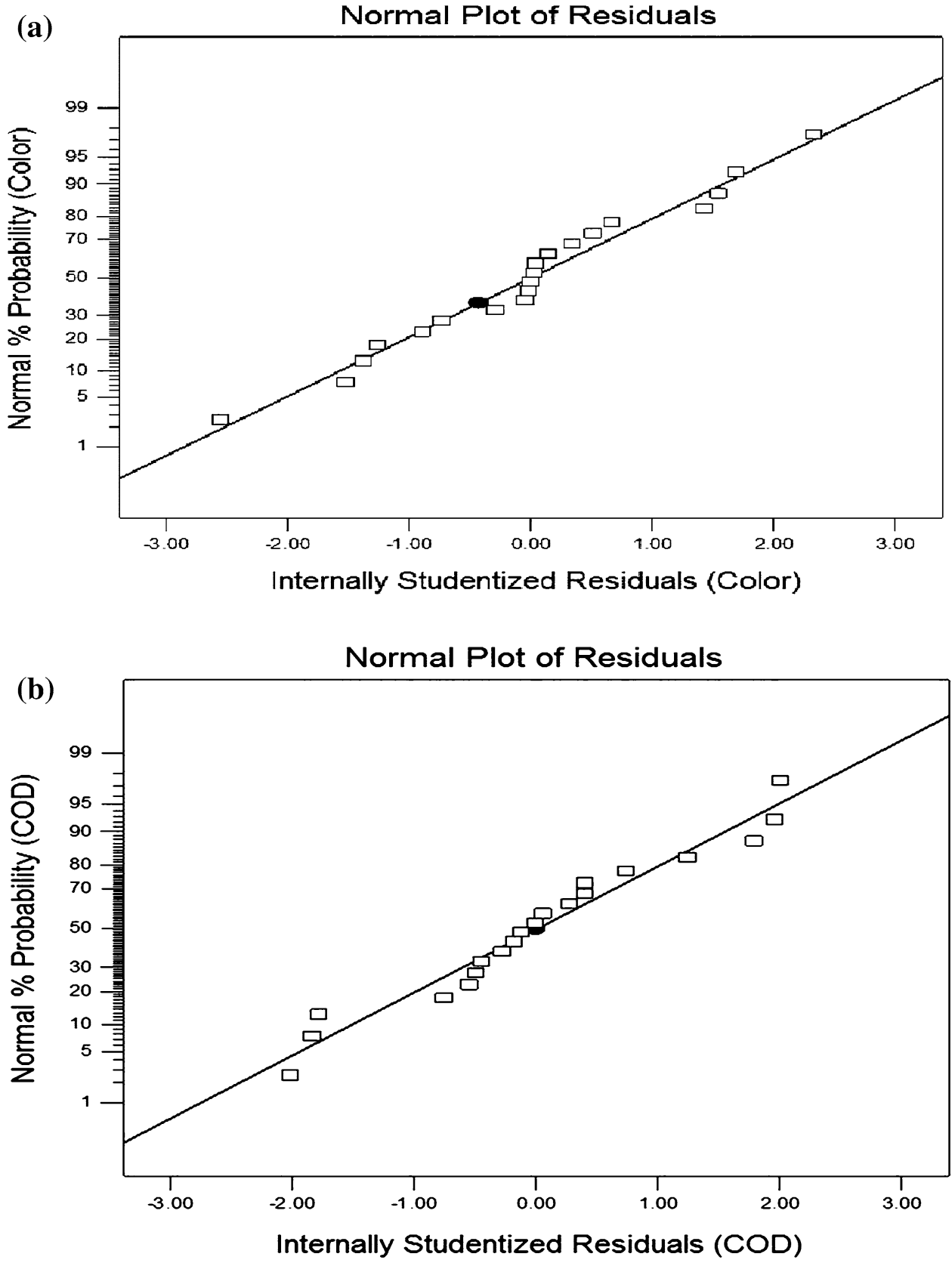
Fig. 2 Scatter diagram of predicted response versus actual $\%$ color and COD removal for the electro-oxidation process (a), (b)
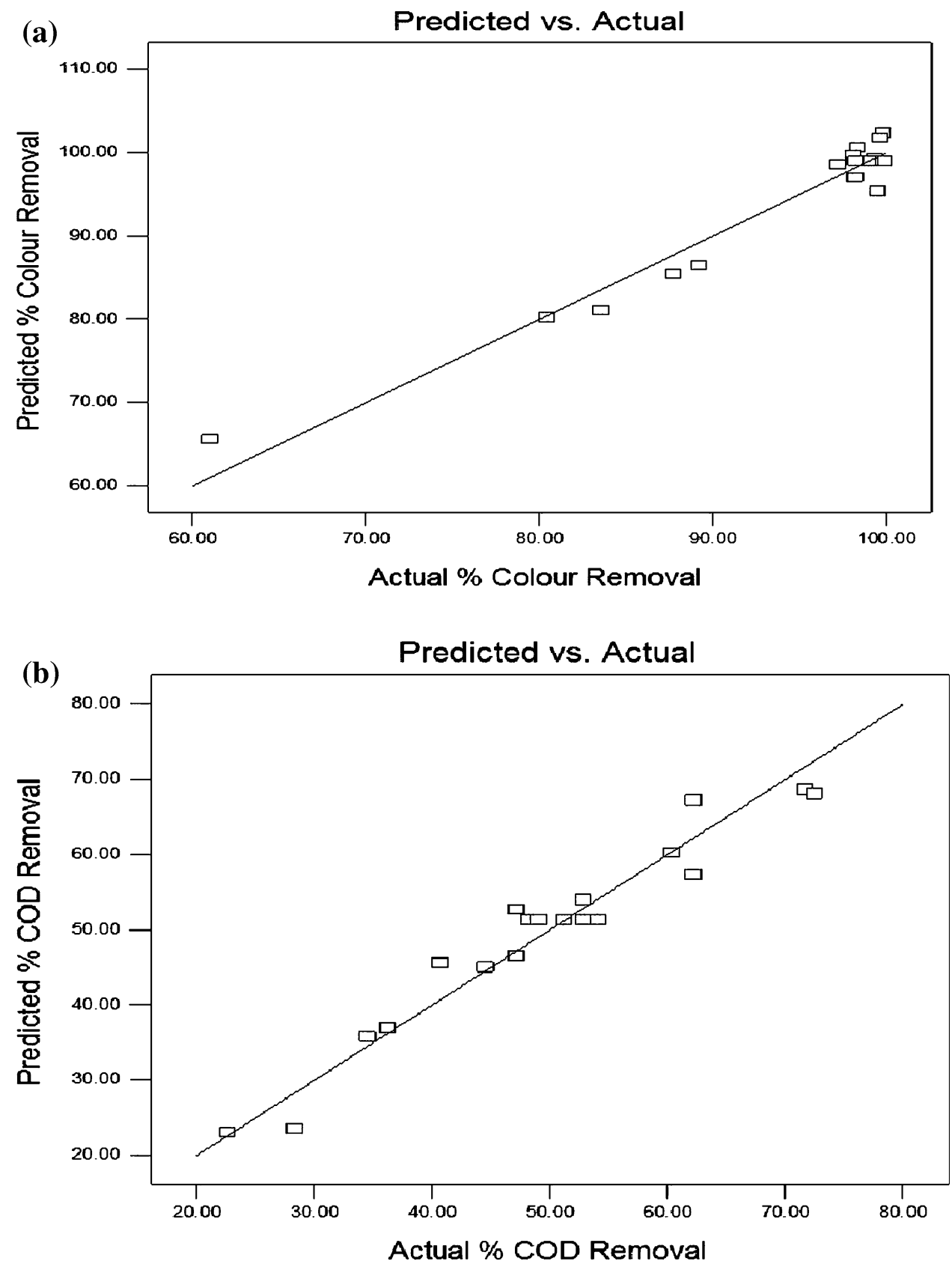

hand, through the comparison of coefficients in Eq. (5), the most significant variables were determined. In this manner, the orders of positive influence of the individual terms on the obtained rate response were $\mathrm{pH}$, $\mathrm{NaCl}$ concentration, and electrolysis time. It can be seen from Eqs. 4 and 5 and the perturbation plot that electrolysis time had curvature effects. It was observed that the interaction between factors and response contour plots are shown in the Figs. 4 and 5. The reaction rate approximately increased linearly with $\mathrm{pH}, \mathrm{NaCl}$ concentration, and electrolysis time in the considered design space.
Response surface plotting for evaluation of operational variables

\section{Effect of initial $\mathrm{pH}$ on color and COD removal}

The 2D contour plot are generally the graphical representation of the regression equation. Figs. 4 and 5 represent the response contour plots of the initial $\mathrm{pH}\left(X_{1}\right), \mathrm{NaCl}$ concentration $\left(X_{2}\right)$, and electrolysis time $\left(X_{3}\right)$ on dye removal efficiency using electro-oxidation processes with initial dye concentration of $500 \mu \mathrm{M}$ and current density of $34.96 \mathrm{mAcm}^{-2}$. 
Fig. 3 Perturbation plot for rate response [for $A \mathrm{pH}, B$ salt $(\mathrm{NaCl}), C$ time (min)]
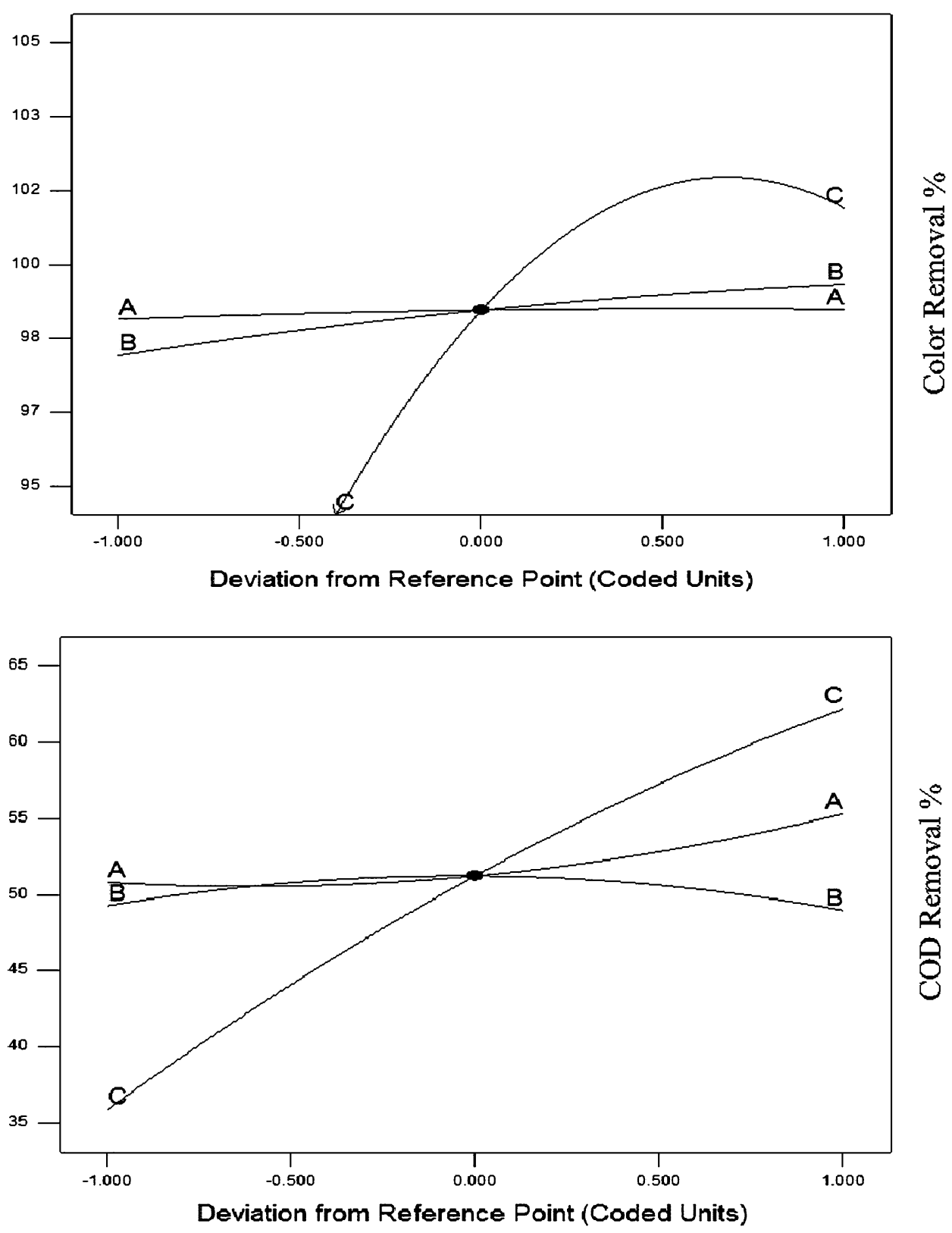

The functional groups of reactive dye are anionic, and they release negative charges after dissolving in water. $\mathrm{pH}$ is also known to affect the structural stability of dye molecules (in particular, the dissociation of their ionizable sites), and therefore their color intensity (Crini and Badot 2008). RY 186, vinyl sulphone as the reactive group and anionic azo dye, gets protonated in acidic medium and deprotonated in basic medium. Therefore, with the decrease of $\mathrm{pH}$, dye protonation processes could lead to reduction of charge density and cause self-aggregation of anionic dye molecules. Figures 4 and 5 show the removal of color $(99 \%)$ and COD $(73 \%)$. At acidic conditions, free chlorine is the dominant oxidizing agent, while at slightly alkaline conditions, hypochlorite, chloride ions, and hydroxyl radicals are all important (Gotsi et al. 2005; Krasnobrodko 1988). The general chloride reactions involved in electrochemical oxidation are (Kim et al. 2003)

$2 \mathrm{Cl}^{-} \rightarrow \mathrm{Cl}_{2}+2 \mathrm{e}^{-}$

$\mathrm{Cl}_{2}+\mathrm{H}_{2} \mathrm{O} \rightarrow \mathrm{HOCl}+\mathrm{H}^{+}+\mathrm{Cl}^{-}$

$\mathrm{HOCl} \rightarrow \mathrm{H}^{+}+\mathrm{ClO}^{-}$

$6 \mathrm{HOCl}+3 \mathrm{H}_{2} \mathrm{O} \rightarrow 2 \mathrm{ClO}_{3}^{-}+4 \mathrm{Cl}^{-}+12 \mathrm{H}^{+}+3 \mathrm{O}_{2}+6 \mathrm{e}^{-}$

$\mathrm{ClO}^{-}+\mathrm{H}_{2} \mathrm{O}+2 \mathrm{e}^{-} \rightarrow \mathrm{Cl}^{-}+2 \mathrm{OH}^{-}$ 
Fig. 4 Contour plots for the effect of $\mathrm{pH}$, electrolyte concentration, and time on color removal

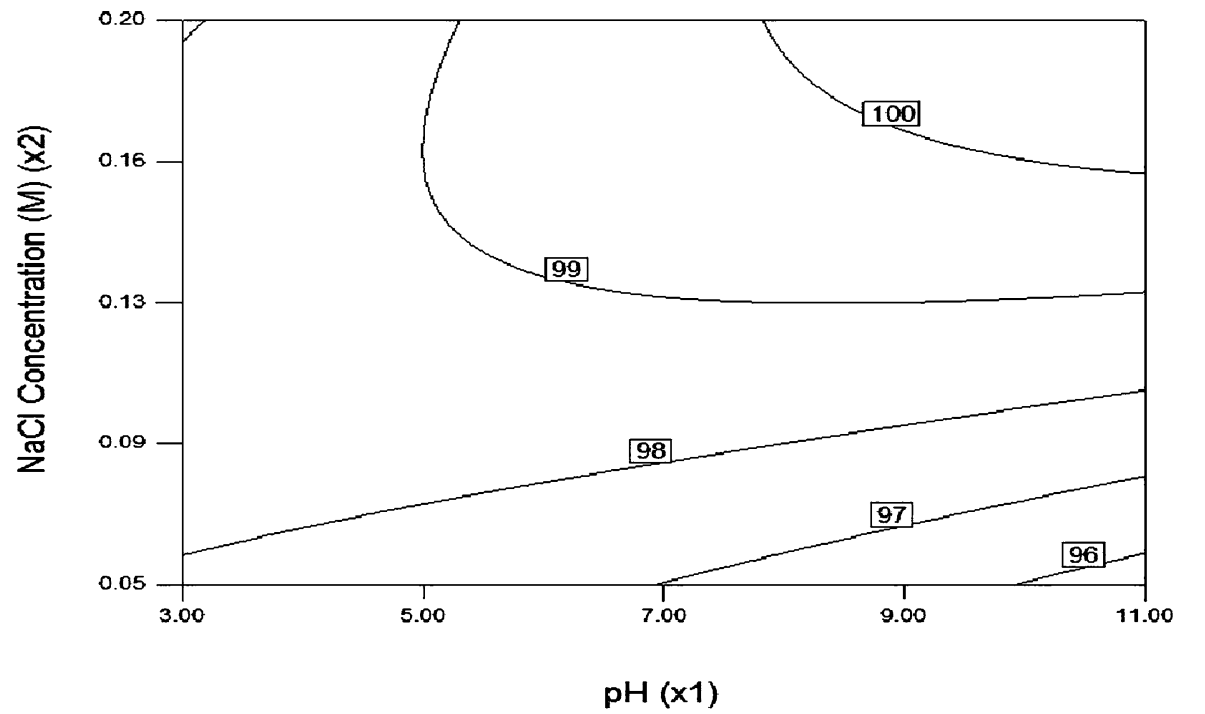

0
0
0
0
0
0
0
0
0
0

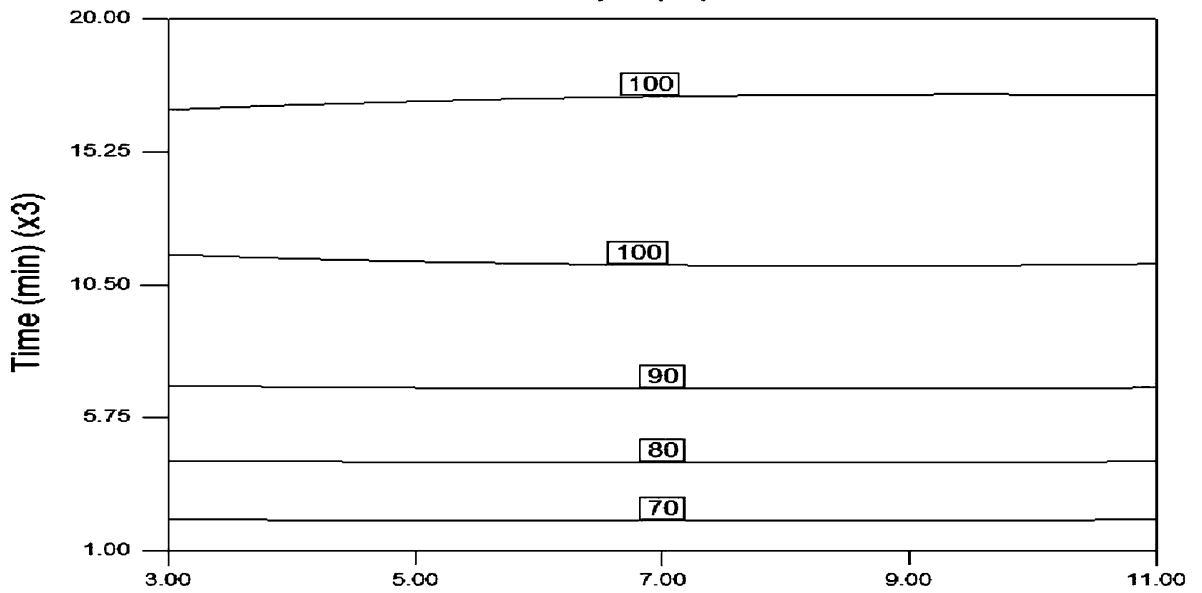

$\mathrm{pH}(\times 1)$

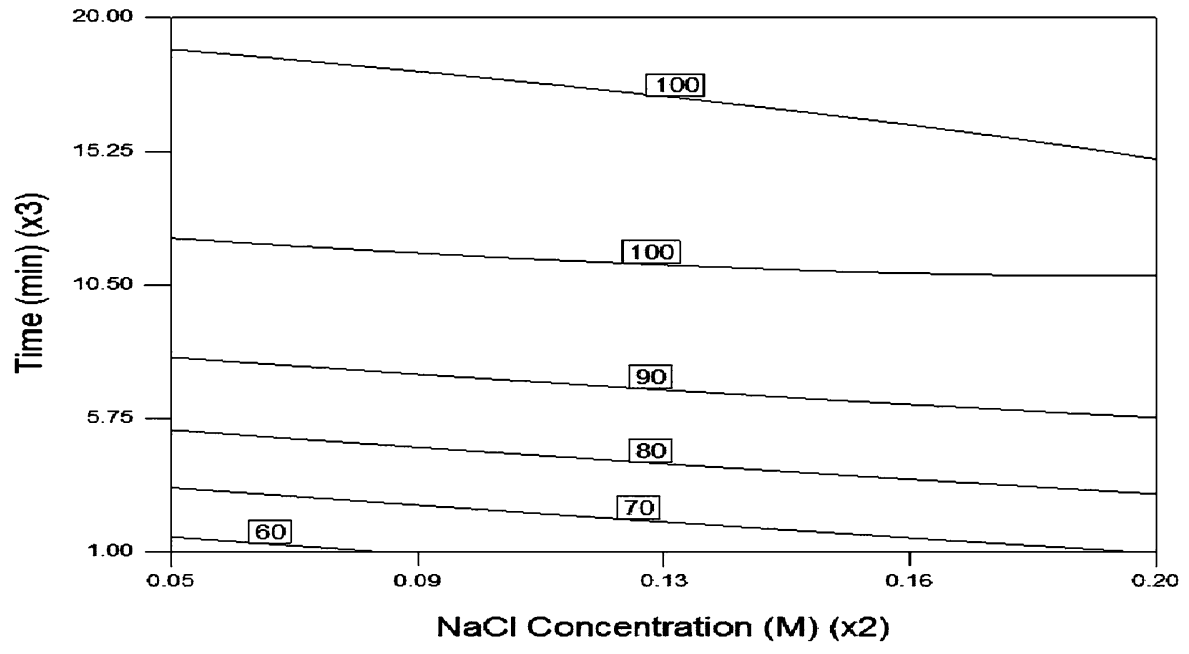

00
0
0
0
0
0
0
0
0
0 
Fig. 5 Contour plots for the effect of $\mathrm{pH}$, electrolyte concentration, and time on COD removal
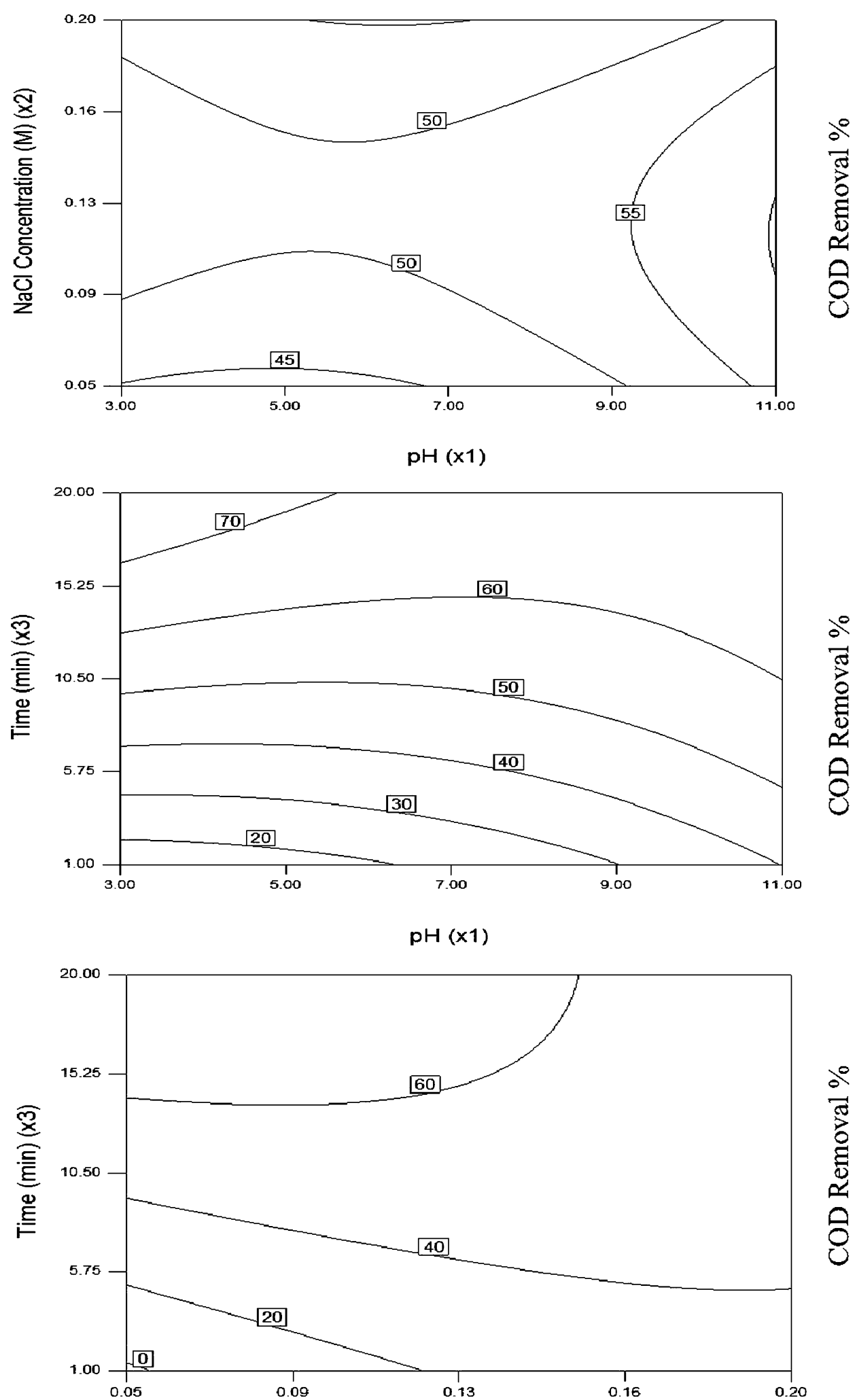

NaCl Concentration (M) (x2) 
Fig. 6 SEM image of graphite anode surface of electrode $\mathbf{a}$ before and $\mathbf{b}$ after electrolysis treatment
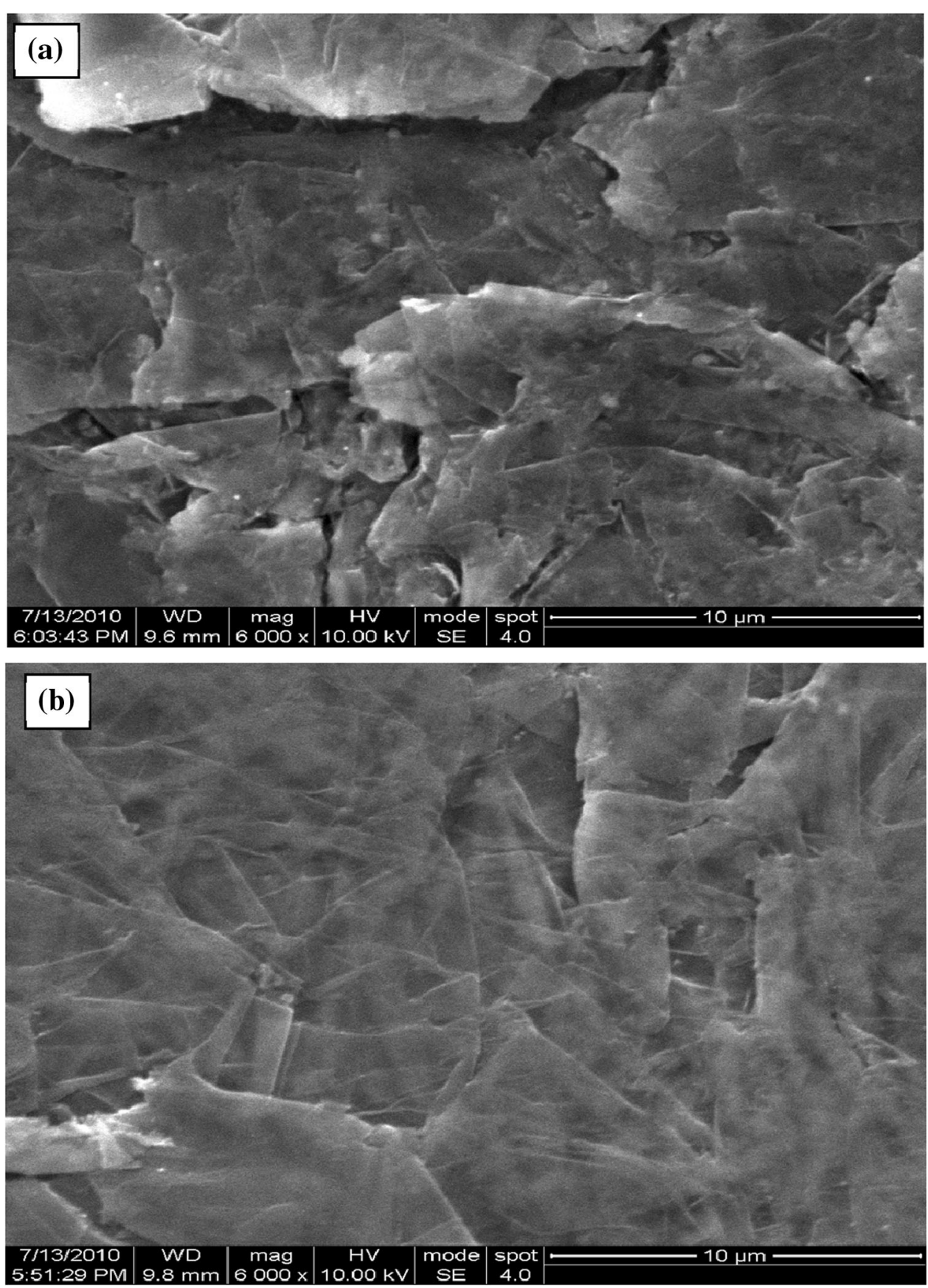

$6 \mathrm{ClO}^{-}+3 \mathrm{H}_{2} \mathrm{O} \rightarrow 2 \mathrm{ClO}_{3}^{-}+4 \mathrm{Cl}^{-}+6 \mathrm{H}^{+}+1.5 \mathrm{O}_{2}+6 \mathrm{e}^{-}$

$2 \mathrm{H}_{2} \mathrm{O}+2 \mathrm{e}^{-} \rightarrow 2 \mathrm{OH}^{-}+\mathrm{H}_{2}$

$\mathrm{R}+\mathrm{HOCl} \rightarrow \mathrm{P}+\mathrm{Cl}^{-} \mathrm{R}$, pollutant; $\mathrm{P}$, product.

Among all these species, $\mathrm{HOCl}$ is the strongest oxidizing agent and therefore electrolysis performed at acidic $\mathrm{pH}$, where its formation should be favored, was expected to result in faster degradation. The study of the influence of $\mathrm{pH}$ confirmed the important role of the electrogenerated active chlorine in the color removal and, indirectly, on the COD abatement, while the mineralization process appeared to be almost $\mathrm{pH}$ insensitive since it was mainly dependent on the oxidizing action of the hydroxyl radical produced on the electrode surface. It can be concluded that, at acidic $\mathrm{pH}$, medium was found to be beneficial to achieve the highest color and COD removals. Considering the highest removal efficiencies, particularly for COD, $\mathrm{pH} 3.9$ was selected as 
the best initial $\mathrm{pH}$ condition for the present application. According to the observed results (Figs. 4 and 5), at lower initial $\mathrm{pH}$ values, relatively high color and COD removal are obtained which is in agreement with this theory.

\section{Effect of electrolytic concentration on color and COD removal}

The removal of pollutants from the wastewater by electrochemical oxidation process accompanying with $\mathrm{NaCl}$ could be mainly attributed to the indirect oxidation effect of chlorine/hypochlorite produced during the electrolysis (Un et al. 2008). In this investigation, the $\mathrm{NaCl}$ concentration varied from 0.05 to $0.2 \mathrm{M}$ at a constant current of $34.96 \mathrm{mAcm}^{-2}$. Figures 4 and 5 show rapid decoloration and indicate that initial azo group dyes are fully degraded, giving smaller and colorless organic or inorganic products, which can further be treated for complete mineralization. It was also reported in the literature that the chromophore groups of dyes are easily destroyed by direct and indirect oxidation, and later the subsequent intermediates and other organics undergo further anodic oxidation at a much lower rate (Naumczyk et al. 2006). In electrochemical degradation of textile dye solutions, the rate of color removal was higher than the COD removal due to the faster azo bond degradation (Naumczyk et al. 2006; Sakalis et al. 2005).

As shown in Figs. 4 and 5, with the increase of $\mathrm{NaCl}$ concentration, the removal efficiency was steadily increased. Higher concentration of $\mathrm{NaCl}$ leads to higher conductivity of aqueous solution, and thus facilitates the passage of electrical current. However, color removal is not proportional to the salt concentration. Low significant influence of the electrolyte concentration was observed on the rate of color removal. However, as the electrolyte concentration increases, the electrical conductivity of the solution increases and thus the electrolytic cell voltage for maintaining a constant current decreases. Consequently, the energy consumption decreased as the electrolyte concentration increased. The higher the chloride concentration, the higher is the production of active chlorine species and, because of this, higher COD removal is achieved. Active chlorine species can react with organic compounds by addition, substitution, and electron transfer (Emmanuel et al. 2004). Researchers also investigated indirect electrooxidation with active chlorine performed with a graphite anode to mainly characterize the decoloration process of several organic dyes such as congo red (Wang 2003), methyl orange (Sanroman et al. 2004) indigo (Comninellis and Nerini 1995), acid orange 10 (Muthukumar et al. 2007), and reactive orange 107 (Rajkumar and Muthukumar 2012).
Effect of electrolysis duration on color and COD removal

In view of reducing the power consumption and optimizing the electrochemical oxidation process, the effects of electrolysis duration on color and COD removal were studied by varying the duration from 1 to $20 \mathrm{~min}$. The results are shown in Figs. 4 and 5. The color and COD removal efficiency depends directly on the concentration of oxidants produced by the electrodes which in turn depends upon time $\left(X_{3}\right)$. When the value of $X_{3}$ increases, an increase occurs in the concentration of active chlorine. Consequently, an increase in the $X_{3}$ in turn increases the color and COD removal efficiency. The decolorization and degradation of the dye are mainly due to the formation of oxidants such as chlorine, ozone, and/or free radicals.

The rapid decolorization indicates that initial dyes are fully degraded, giving smaller and colorless organic or inorganic products, which can further be treated for complete mineralization. Among the dye molecule, the nitrogen atoms of azo and heterocyclic aromatic ring amines are easy to oxidize. As revealed by various researchers on the electro-oxidation of azo dyes, the chromophore azo group is easily broken to generation $\mathrm{N}_{2}$ gas (reaction 14):

$\mathrm{R}-\mathrm{N}=\mathrm{N}-\mathrm{R}^{\prime}+2 \mathrm{OH} \quad \mathrm{N}_{2}(\mathrm{~g})+\mathrm{ROH}+\mathrm{R}^{\prime} \mathrm{OH}$

However, the complete decolorization of the dye does not show complete COD removal. The decrease of COD shows that further degradation of the initial colorless products occurred along with the decolorization during the electrochemical treatment. It could be concluded that the rate of COD removal is lower than that of color removal, indicating that the azo bond degradation is the first step of the electrochemical degradation mechanism with the comparison of COD removal. The COD value of $73 \%$ indicates that the removal degree for color disappearance

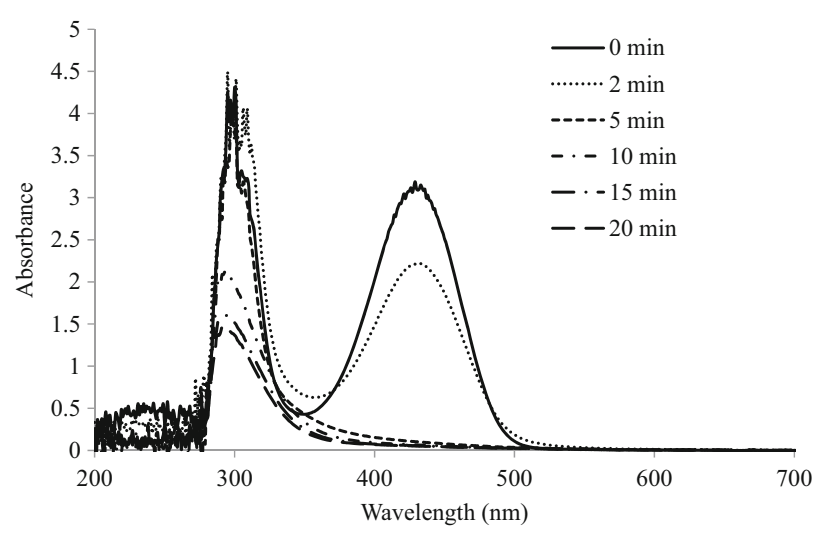

Fig. 7 UV-Vis spectrum of C.I.RY 186 at different electrolysis times 
Fig. 8 FTIR spectrum of RY 186 before (a) and after treatment (b)
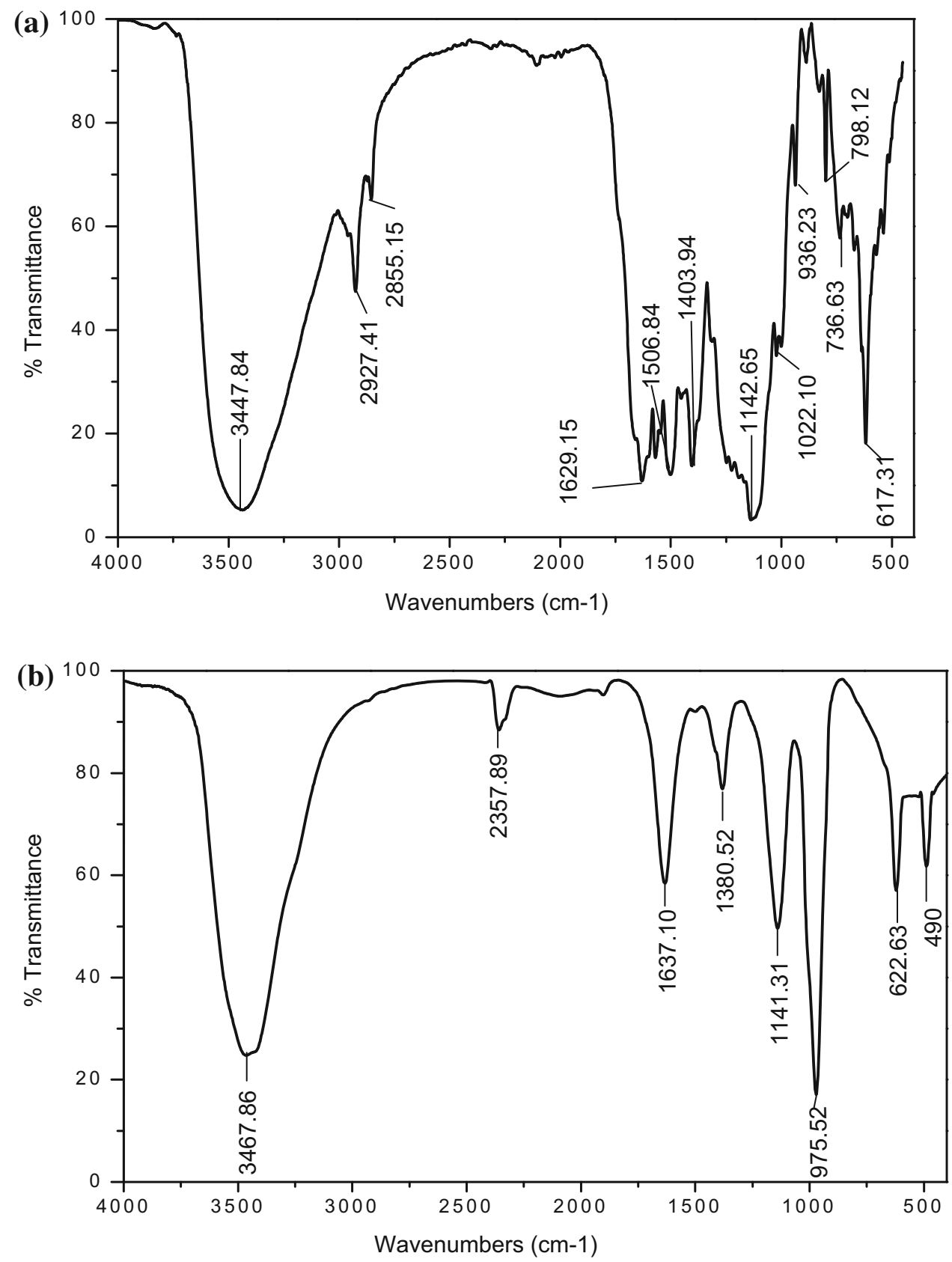

does not mean complete degradation or complete removal of pollutants in the aqueous solution.

\section{SEM analysis of electrodes}

The SEM image of the graphite sheet electrode (anode) before and after electrochemical treatment was obtained to compare their surface texture. Figure 6a shows the fresh graphite sheet surface prior to its use in electrochemical experiments. The surface of the anode indicates the flaky structure of the material. The flakes have numerous grain boundaries, and their orientation was observed to be very random (Bhaskar Raju et al. 2008). Figure $6 \mathrm{~b}$ shows the SEM of the same anode after several cycles of its use in electrochemical experiments for a total duration of $4 \mathrm{~h}$. After electro-oxidation process, its observed that the surface of anode which was flaky and scattered had been changed to uniform micro-flaky surface. This indicates that, during the electro-oxidation process, the appearance of the anode changed from the gray color to black flaky deposit on the surface of the electrode. 
UV-Visible spectra studies

The changes in absorbance characteristics of RY 186 during the electro-oxidation process were investigated, and the results are shown in Fig. 7. The optimum conditions obtained from the statistical analysis $\mathrm{pH} 3.9$ and $\mathrm{NaCl}$ concentration $0.11 \mathrm{M}$ were considered and the experiment was performed. The peak disappeared gradually during the electrolysis at $425 \mathrm{~nm}$ which confirms the decolorization. The formation of new peak at $288 \mathrm{~nm}$ at the end of the electrolysis shows that the mineralization of the RY 186 is not completely achieved. The peak can be attributed to

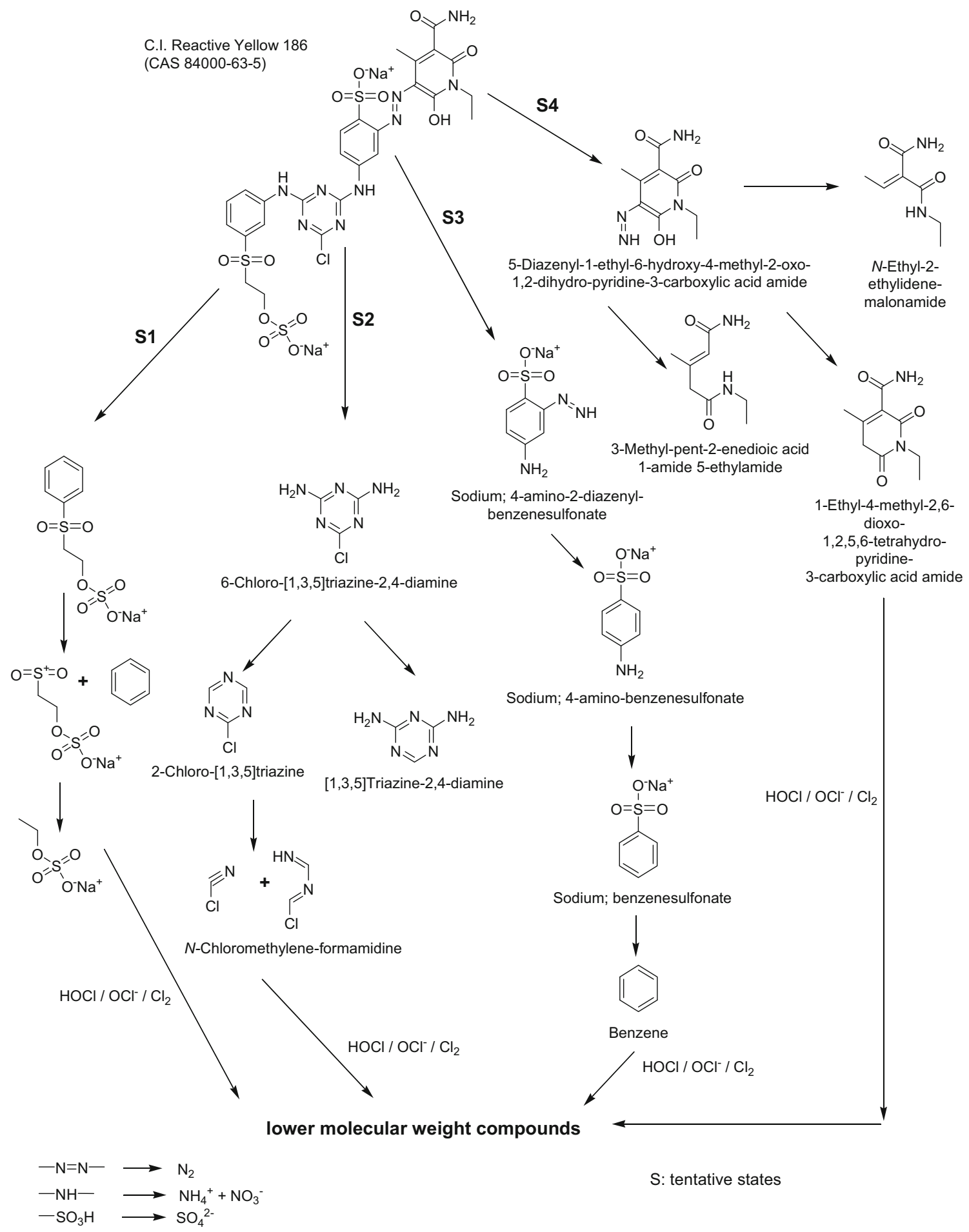

Fig. 9 Proposed pathways of Reactive Yellow 186 degradation during electrochemical oxidation process 
carboxylic acids accumulated at the final stage of the oxidation. This represents the residual COD present in the aqueous solution.

\section{FTIR studies}

The FTIR spectral comparison between the initial dye and samples extracted at optimum condition. Figure 8 shows the IR spectra of the dye powder and after electrolysis. The residue obtained during the process indicates that the structural changes might occur during the electro-oxidation process. In Fig. 8a, several bands can be distinguished in the spectra on initial RY 186 powder. The peak at $3447.84 \mathrm{~cm}^{-1}$ indicates the presence of both free and hydrogen-bonded $\mathrm{OH}$ groups and the peak at $2927.41 \mathrm{~cm}^{-1}$, which represent the $\mathrm{C}-\mathrm{H}$ symmetric stretching and $\mathrm{C}-\mathrm{H}$ asymmetric stretching of $\mathrm{CH}_{2}$, respectively (Dignac et al. 2000), the peak becoming weaker near $1629.15 \mathrm{~cm}^{-1}$, which is responsible for the combination of stretching vibration of $\mathrm{C}=\mathrm{O}$ conjugated with $\mathrm{C}=\mathrm{C}$ (Miao and Tao 2008). The appearance of peak at $1506.84 \mathrm{~cm}^{-1}$ indicates the presence of azo group. The vibrations located at $1506.84 \mathrm{~cm}^{-1}[\mathrm{~N}=\mathrm{N}$ bond vibrations or aromatic ring vibrations sensitive to the interaction with the azo bond, or the bending vibration mode $\delta(\mathrm{N}-\mathrm{H})$ of the azo dye] and other peaks were also noticed at $1403.94 \mathrm{~cm}^{-1}$, which corresponds to $\mathrm{O}=\mathrm{S}=\mathrm{O}$ stretching. The bond at $936.23 \mathrm{~cm}^{-1}$ corresponds to the Na. A peak at $796.33 \mathrm{~cm}^{-1}$ confirms the presence of chloride. The peaks of the wave number between 750 and $610 \mathrm{~cm}^{-1}$ denote aromatic or benzene ring. Figure $8 \mathrm{~b}$ shows that after treatment, the broad peak around $3467.86 \mathrm{~cm}^{-1}$, which assigns to $\mathrm{N}-\mathrm{H}$ vibration (Seferoglu et al. 2008), and the peaks 2927, 2855, 1506, 1403, 1022,736 , and $617 \mathrm{~cm}^{-1}$ get completely disappeared. Surprisingly, the peaks at $2357.8 \mathrm{~cm}^{-1}$, which typically characterize $\mathrm{CO}_{2}$, were presented after electro-oxidation. The appearance of peak at $1637.10 \mathrm{~cm}^{-1}$ indicates the presence of $\mathrm{C}=\mathrm{O}$ in carboxylic group, aldehydes, or ketones (Zhang et al. 2005). The other peak at $1380.52 \mathrm{~cm}^{-1}$ indicates the presence of $\mathrm{C}=\mathrm{H}$. The formation of new peaks at 1141.31 and $975.52 \mathrm{~cm}^{-1}$ indicates the $\mathrm{C}-\mathrm{NO}_{2}$ of aromatic ring and $\mathrm{C}-\mathrm{N}$ stretching of aromatic $\mathrm{NO}_{2}$. The peak at $622.63 \mathrm{~cm}^{-1}$ is thought to belong to $\mathrm{C}-\mathrm{Cl}$. This variation in the FTIR spectra has explained the incomplete mineralization of RY 186.

\section{GC-MS spectra}

Quantitative analysis of the intermediates is helpful to get a better understanding of the mechanism of the electrooxidation process.The intermediate compounds formed during the degradation of RY 186 were identified by GCMS. A preparative experiment was carried out with initial concentration of the dye $500 \mu \mathrm{M}$ and $0.11 \mathrm{M} \mathrm{NaCl}$ as a supporting electrolyte at a constant applied current density of $34.96 \mathrm{mAcm}^{-2}$ and initial $\mathrm{pH}$ 3.9. Considering the identified fragments, it is expected that four pathways (S1S4) are involved, as shown in Fig. 9. The fragments, which formed in the first step bonds the $\mathrm{C}-\mathrm{N}$ and $\mathrm{C}-\mathrm{N}$ in the RY 186 molecule, were probably cleaved by free radical attack, which led to the decoloring of RY 186 in the bulk solution. On the basis of GC-MS findings; a possible degradation pathway for the C.I. RY 186 (S1-S4) such as 5-Diazenyl-1ethyl-6-hydroxy-4-methyl-2-oxo-1,2-dihydro-pyridine-3carboxylic acid amide, Sodium; 4-amino-2-diazenyl-benzenesulfonate, and 6-Chloro-[1,3,5] triazine-2,4-diamine, and further fractions that correspond to the Sodium; benzenesulfonate, benzene, aliphatic, and carboxylic acids. Earlier studies suggested that the azo group was decomposed due to the elimination of molecular nitrogen (Gahr et al. 1994). However, this result indicated that the azo group might be converted to ammonia and nitrate ion simultaneously. Benzene is subsequently attacked by $\mathrm{OH}^{\bullet}$ radicals to form phenol which can submit an oxidative opening of the aromatic ring leading to low molecular weight aliphatic carboxylic acids, such as formic and acetic acid. The final steps involve the oxidation of carboxylic acids which can easily be changed to $\mathrm{CO}_{2}$ and $\mathrm{H}_{2} \mathrm{O}$ leading to complete mineralization of recalcitrant organic dye molecules.

\section{Conclusion}

A systematic optimization protocol to find optimal operation conditions for simultaneous removal of azo dye C.I.RY 186 in the electro-oxidation process was proposed. The optimum operational conditions were found to be at $\mathrm{pH} 3.9, \mathrm{NaCl}$ concentration of $0.11 \mathrm{M}$, electrolysis time $18 \mathrm{~min}$, and the current density at $34.96 \mathrm{mAcm}^{-2}$. Analysis of variance showed that a second-order polynomial regression model could properly interpret the experimental data with coefficient of determination for color and COD removal $\left(R^{2}\right)$ value of 0.9556 and 0.9416 , respectively, and an $F$-value of 23.93 and 17.92, respectively. The maximal decolorization efficiency of $99 \%$ and COD removal $73 \%$ were achieved. Comparison of UV-Vis and FTIR spectra revealed significant changes in peak positions, and the intermediates detected by GC-MS, the azo bond of the dye structure was the first potentially broken when the azo bond was attacked, which led to the decolorization of the dye. With the help of hydroxyl radical and other radicals, the intermediates continued to be degraded to carbon dioxide and water, which led to the mineralization of the dye solution. This result implicates that the optimization using RSM based on the CCD can save the time and effort for a maximum removal of dye in wastewater. 
Acknowledgments The author K. Rajkumar (CSIR - SRF-09/ 472(0144)/2010-EMR-I) is grateful to the Council of Scientific and Industrial Research, Government of India, New Delhi for financial support. The authors are thankful to Department of Science and Technology, Government of India, New Delhi for financial assistance.

Open Access This article is distributed under the terms of the Creative Commons Attribution License which permits any use, distribution, and reproduction in any medium, provided the original author(s) and the source are credited.

\section{References}

Aktas N, Boyaci IH, Mutlu M, Tanyolac A (2006) Optimization of lactose utilization in deproteinated whey by Kluyveromyces marxianus using response surface methodology (RSM). Bioresour Technol 97:2252-2259

Bhaskar Raju G, Thalamadai Karuppiah M, Latha SS, Parvathy S, Prabhakar S (2008) Treatment of wastewater from synthetic textile industry by electrocoagulation-electrooxidation. Chem Eng J 144:51-58

Clesceri LS, Greenberg AE, Eaton AD (1998) Standard methods for the examination of water and wastewater, 20th edn. American Public Health Association, Washington, DC

Comninellis C, Nerini A (1995) Anodic oxidation of phenol in the presence of $\mathrm{NaCl}$ for wastewater treatment. J Appl Electrochem 25:23-28

Crini G, Badot PM (2008) Application of chitosan, a natural aminopolysaccharide, for dye removal from aqueous solutions by adsorption processes using batch studies: a review of recent literature. Prog Polym Sci 33:399-447

Dignac MF, Derenne S, Ginestet P, Bruchet A, Knicker H, Largeau C (2000) Determination of structure and origin of refractory organic matter in bioepurated wastewater via spectroscopic methods. Comparison of conventional and ozonation treatments. Environ Sci Technol 34:3389-3394

Emmanuel E, Keck G, Blanchard JM, Vermande P, Perrodin Y (2004) Toxicological effects of disinfections using sodium hypochlorite on aquatic organisms and its contribution to AOX formation in hospital wastewater. Environ Int 30:891-900

Gahr F, Hermanutz F, Oppermann W (1994) Ozonation: an important technique to comply with new German laws for textile wastewater treatment. Water Sci Technol 30:255

Gotsi M, Kalogerakis N, Psillakis E, Samaras P, Mantzavinos D (2005) Electrochemical oxidation of olive oil mill wastewaters. Water Res 39:4177-4187

Huiping L, Guoqun Z, Shanting N, Yiguo L (2007) Technologic variables optimization of gas quenching process using response surface method. Comput Mater Sci 38(3):561-570

Kim T, Parka C, Shinb EB, Kim S (2003) Effects of Cl-based chemical coagulants on electrochemical oxidation of textile wastewater. Desalination 155:59-65

Korbahti BK, Rauf MA (2008) Application of response surface analysis to the photolytic degradation of basic red 2 dye. Chem Eng J 138:166-171

Krasnobrodko IG (1988) Destruction treatment of wastewater from dyes. Chimia, Leningrad (in Russian ed.)

Liu HL, Chiou YR (2005) Optimal decolorization of Reactive Red 239 by $\mathrm{UV} / \mathrm{TiO}_{2}$ photocatalytic process coupled with response surface methodology. Chem Eng J 112:173-179

Liu L, Zhao G, Pang Y, Lei Y, Gao J, Liu M (2010) Integrated biological and electrochemical oxidation treatment for high toxicity pesticide pollutant. Ind Eng Chem Res 49:5496-5503

Miao H, Tao W (2008) Ozonation of humic acid in water. J Chem Technol Biotechnol 83:336-344
Muthukumar M, Sargunamani D, Selvakumar N, Venkata Rao J (2004) Optimisation of ozone treatment for colour and COD removal of acid dye effluent using central composite design experiment. Dyes Pigm 63:127-134

Muthukumar M, Thalamadai Karuppiah M, Bhaskar Raju G (2007) Electrochemical removal of CI acid orange 10 from aqueous solutions. Sep Purif Technol 55:198-205

Myers RH, Montgomery DC (2002) Response surface methodology: process and product optimization using designed experiments, 2nd edn. Wiley, USA

Naumczyk J, Szpyrkowicz L, Zilio-Grandi F (2006) Electrochemical treatment of textile wastewater. Water Sci Technol 34:17-24

Rajkumar K, Muthukumar M (2012) Optimization of electro-oxidation process for the treatment of reactive orange 107 using response surface methodology. Environ Sci Pollut Res 19:148-160

Sakalis A, Mpoulmpasakos K, Nickel U, Fytianos K, Voulgaropoulos A (2005) Evaluation of a novel electrochemical pilot plant process for azo dyes removal from textile wastewater. Chem Eng J 111:63-70

Sanroman MA, Pazos M, Cameselle C (2004) Optimisation of electrochemical decolourisation process of an azo dye, methyl orange. J Chem Technol Biotechnol 74:1349-1353

Seferoglu Z, Ertan N, Hokelek T, Sahin E (2008) The synthesis, spectroscopic properties and crystal structure of novel, bishetarylazo disperse dyes. Dyes Pigm 77:614-625

Segurola J, Allen NS, Edge M, Mahon AM (1999) Design of eutectic photo initiator blends for UV/curable acrylated printing inks and coatings. Prog Org Coat 37:23-37

Soloman PA, Ahmed Basha C, Velan M, Ramamurthi V, Koteeswaran K, Balasubramaniam N (2009) Electrochemical degradation of remazol black $\mathrm{B}$ dye effluent. Clean 37(11):889-900

Un UT, Altay U, Savas Koparal A, Ogutveren UB (2008) Complete treatment of olive mill wastewaters by electrooxidation. Chem Eng J 139:445-452

USEPA (1995) Pollution prevention studies in the textile wet processing industry, Virginia, USA

Wang C (2003) Decolorization of congo red with three-dimensional flow-by packed-bed electrodes. J Environ Sci Health Part AToxic/Hazard. Subst Environ Eng 38(2): 399-413

Yahia Cherif L, Yahiaoui I, Aissani-Benissad F, Madi K, Benmehdi N, Fourcade F, Amrane A (2014) Heat attachment method for the immobilization of $\mathrm{TiO}_{2}$ on glass plates: application to photodegradation of basic yellow dye and optimization of operation parameters, using response surface methodology. Ind Eng Chem Res 53(10):3813-3819

Yahiaoui I, Aissani-Benissad F, Fourcade F, Amrane A (2012) Response surface methodology for the optimization of the electrochemical degradation of phenol on $\mathrm{Pb} / \mathrm{PbO}_{2}$ electrode. Environ Prog Sustain Energy 31(4):515-523

Yahiaoui I, Aissani-Benissad F, Madi K, Benmehdi N, Fourcade F, Amrane A (2013) Electrochemical pre-treatment combined with biological treatment for the degradation of methylene blue dye: $\mathrm{Pb} / \mathrm{PbO}_{2}$ electrode and modeling-optimization through central composite design. Ind Eng Chem Res 52:14743

Yahiaoui I, Aissani-Benissad F, Fourcade F, Amrane A (2014) Combination of an electrochemical pretreatment with a biological oxidation for the mineralization of nonbiodegradable organic dyes: basic yellow 28 dye. Environ Prog Sustain Energy 33:160

Zhang SJ, Yu HQ, Li QR (2005) Radiolytic degradation of acid orange 7: a mechanistic study. Chemosphere 61:1003-1011

Zollinger H (1987) Color chemistry: syntheses, properties and applications of organic dyes and pigments. $\mathrm{VCH}$, New York 